\title{
Low dose ketamine infusion for pediatric hematology/oncology patients: case series and literature review
}

\author{
Helena $\mathrm{Yu}^{1}$, Allen $\mathrm{Chen}^{2}$, Eric Chen ${ }^{2}$, L. Stephen Long $^{1}$, and Anurag Agrawal ${ }^{1}$ \\ ${ }^{1}$ UCSF Benioff Children's Hospital Oakland \\ ${ }^{2}$ University of California Berkeley
}

November 5, 2020

\begin{abstract}
Background: Management of refractory pain in pediatric sickle cell disease (SCD) and oncology is reliant on opioids though high opioid dosing increases side effects and tachyphylaxis. We introduced low dose ketamine infusion (LDKI) to our inpatient unit to determine if LDKI was safe and tolerable. We subsequently hypothesized that LDKI would improve pain scores but not decrease opioid utilization. Procedure: We retrospectively reviewed inpatients from LDKI initiation in March 2014 through October 2017, analyzing each patient's first admission with LDKI. The day prior to LDKI initiation was compared with the day of LDKI initiation and two subsequent days in regard to cumulative daily opioid utilization, vital signs and pain scores. For patients with SCD, the LDKI admission was compared with up to three admissions in the prior year for a vaso-occlusive event. Results: Nineteen patients (12 oncology, $7 \mathrm{SCD}$ ) with a median age of 14.6 years received LDKI for a median of 6 days at a median initial dose of $0.06 \mathrm{mg} / \mathrm{kg} / \mathrm{h}(1.1 \mathrm{mcg} / \mathrm{kg} / \mathrm{min})$. There was no change in pain scores, heart rate or opioid utilization when comparing the day prior to LDKI initiation with subsequent days. No patient discontinued LDKI due to intolerability. For patients with SCD, there was a median $32 \%$ reduction in cumulative pain scores when comparing the LDKI admission with prior admissions. Conclusions: LDKI is well tolerated and may be a viable option for refractory pediatric cancer- and sickle cell-related pain. Future study is required to further delineate appropriate dosing and patients most likely to benefit.
\end{abstract}

\section{INTRODUCTION}

The management of pain in patients with sickle cell disease remains incomplete and heavily reliant on opioid therapy. [1] Similarly, pediatric oncology patients with refractory pain due to severe mucositis, bone pain due to tumor or metastases and end of life pain have limited utilized treatment options beyond opioids. [2] For accredited hospitals, The Joint Commission requires pain management standards inclusive of assessment of pain interventions with the goal of improving quality of care and decreasing adverse effects of opioid usage, especially with increasing dosages. [3] High opioid doses for intractable cancer pain and chronic sickle cell related pain are often ineffective and should be avoided due to tachyphylaxis and increasing side effects including sedation, constipation, respiratory depression, hyperalgesia, allodynia, myotonia and seizure. [4-6] Chronic opioid utilization leads to tolerance due to downregulation of N-methyl-?-aspartate (NMDA) receptors in the spinal cord. [7] As a NMDA receptor antagonist, ketamine may have beneficial effect on opioid tolerance and hyperalgesia and act synergistically with morphine. [4,7] Ketamine additionally has antidepressive effects through its NMDA receptor blockade. [8] Ketamine is rapidly metabolized and highly bioavailable when given intravenous or intramuscular. [8] Multiple publications have reported utilization of subanesthetic continuous infusion ketamine (i.e., [?] $1 \mathrm{mg} / \mathrm{kg} / \mathrm{h}$ ) in pediatric sickle cell, oncology and chronic pain patients at doses ranging from $0.02-0.4 \mathrm{mg} / \mathrm{kg} / \mathrm{h}$ (Table 1). [4, 9-23] These studies while generally retrospective have shown low dose ketamine infusion to be well tolerated with subjective benefit in some patients without overall impact on opioid utilization. Based on this literature, we developed a quality improvement initiative to introduce low dose ketamine infusion (LDKI) to our hematology/oncology inpatient 
unit. We subsequently aimed to determine if LDKI was safe and tolerable in our population and hypothesized that LDKI would improve pain scores but not decrease opioid utilization. Here we review our institutional experience and the relevant literature to date.

\section{METHODS}

We designed a protocol as a quality improvement initiative for introduction of LDKI for refractory or chronic pain (Supporting information) in 2014 for our pediatric and young adult hematology and oncology patients at UCSF Benioff Children's Hospital Oakland. Protocol development occurred with involvement of the pain anesthesiologist, palliative care team, hematology/oncology, nursing and pharmacy to provide LDKI at a dose of $1-10 \mathrm{mcg} / \mathrm{kg} / \mathrm{min}(0.06-0.6 \mathrm{mg} / \mathrm{kg} / \mathrm{h})$, with patients generally being prescribed $1-5 \mathrm{mcg} / \mathrm{kg} / \mathrm{min}$ unless with chronic refractory pain or at end of life (Supplemental material). We subsequently obtained institutional review board (IRB) approval to retrospectively review our initial experience from protocol initiation in March 2014 through October 2017, when IRB approval was obtained for hematology/oncology patients through age 21 years prescribed LDKI. Patients were included during their first admission with LDKI. There were no exclusion criteria.

For these patients, their primary diagnosis and reason for admission were recorded in addition to all concomitant scheduled and as-needed medications (opioid and non-opioid) with a focus on use on benzodiazepines for LDKI side effects. Cumulative daily (24 hour) opioid doses were converted to morphine equivalents. Vital signs and pain scores from up to five days before and after initiation of LDKI were recorded and averaged in 24-hour increments. The day of initiation of LDKI was designated day 0 and compared with the day prior to LDKI initiation as well as day 1 and 2 after LDKI initiation to determine if there was a significant daily decrease in opioid utilization, pain scores or heart rate. Given the inter-patient variability and the fact that most all patients with sickle cell disease (SCD) were initiated on LDKI at time of admission, these patients were compared with prior admissions for a vaso-occlusive event (VOE), with a maximum of three admissions recorded within one year prior to the admission in which they received LDKI. These admissions were reviewed to determine if there was a significant decrease in pain scores, opioid utilization or hospital length of stay in the LDKI admission as compared with the prior admissions. Daily physician and nursing progress notes were reviewed for subjective descriptions of each patient's pain and any reported side effects to ketamine. Given the small sample size, data were compared using medians and Mann Whitney U testing. Friedman test for repeated measures was utilized when there were repeated days with the same number of data points.

\section{RESULTS}

Nineteen patients (12 oncology, 7 sickle cell) with a median age of 14.6 years received LDKI for a median of 6 days at a median initial dose of $0.06 \mathrm{mg} / \mathrm{kg} / \mathrm{h}(1.1 \mathrm{mcg} / \mathrm{kg} / \mathrm{min})$ (Table 2). Patients with SCD were all admitted for a VOE and only 2 of the 7 were on opioids (for 1 and 3 days) prior to initiation of LDKI. The other 5 patients were initiated on LDKI on the day of admission with opioids. For patients with both sickle cell disease and cancer, there was no significant change in pain scores, heart rate or opioid utilization when comparing the day prior to LDKI initiation (for oncology patients), the day of LDKI initiation, and the two subsequent days after LDKI initiation (Table 3). No patient developed hypertension or discontinued the LDKI due to intolerability. Four patients had a single side effect each including two with dream-like feeling (dysphoria) and one each with blurry vision and drowsiness, one of which required LDKI dose reduction and none of which were treated with benzodiazepines. For patients with SCD, comparing the LDKI admission with prior admissions did not show a significant difference in pain scores, opioid utilization or hospital length of stay though there was a median $32 \%$ reduction in pain scores when comparing the entire admission with LDKI to the prior admissions (Table 4).

\section{DISCUSSION}

Similar to prior publications in pediatric hematology/oncology patients, we were able to show that patients initiated on LDKI tolerated the infusion without significant side effects resulting in LDKI discontinuation. Patients utilized LDKI for a median of 6 days (IQR 4,11) also signifying tolerability. Also similar to prior 
publications, LDKI did not impact opioid utilization. Although we did not show that there was a significant impact on pain scores, there may have been a clinically meaningful, subjective reduction in pain. Overall, there was a $30 \%$ reduction in median pain scores when comparing the entire cohort on the day of LDKI initiation (day 0) and the subsequent day (day 1). Similarly, when comparing patients with sickle cell disease receiving LDKI to prior admissions without LDKI, there was a $32 \%$ reduction in median pain scores, though this was underpowered to reach significance.

Studies attempting to define clinically meaningful pain reduction are limited. Generally, a 30\%-50\% decrement in pain scores is considered clinically meaningful, though cannot be generalized to the individual patient. [24] In studies in both acute, post-operative pain as well as chronic pain, a decrement in the visual analog scale of $20 \%$ corresponded to minimal improvement, while $30 \%-35 \%$ decrement corresponded to much improvement. [25-26] Myrvik et al. [27] note in a small pediatric SCD cohort that a decrement in the visual analog scale of $0.97 \mathrm{~cm}$ and 0.9 in the numeric rating scale was the minimum clinically significant improvement. Numerical pain rating scales are limited due to being a unidimensional assessment of pain at one moment in time in patient cohorts with dissimilar pain tolerance and medication response. [28] As noted by Nobrega et al. [18] in their study of pediatric patients with sickle cell disease, there are significant inter-patient differences in response to LDKI; therefore, there may be a subset of patients more likely to benefit but not yet clearly delineated.

Prior studies with LDKI in pediatric hematology/oncology patients (Table 1) have similarly struggled to define an objective response for multiple reasons: 1) studies were almost all retrospective; 2) patients with end-stage cancer had increasing pain due to their underlying condition; 3) patients' pain may have naturally improved over time and improvement unnecessarily attributed to LDKI initiation (i.e., regression to the mean); 4) multiple different measures were utilized to define which pre-LDKI and post-LDKI pain scores to compare; and 5) challenges of generalizing an intervention with significant inter-patient variability. The single recent multicenter prospective observational trial by Courade et al. [9] in pediatric and young adult cancer patients reported meaningful benefit in pain scores when comparing the day of LDKI initiation and two days later. Given the rapid onset of action of LDKI, two days may or may not be an appropriate time frame to measure response. More important though, $47 \%$ of patients found LDKI to be "very helpful," which further argues that the objective response was real, at least for some of the patients. Nobrega et al. [18] reported a meaningful reduction in pain scores in a large cohort of pediatric patients with sickle cell disease, but this was comparing baseline pain scores with pain scores taken after LDKI discontinuation, which was several days later and could be attributed to the natural improvement in patient symptoms. The two retrospective studies of patients with chronic pain reported improvement in pain scores immediately following LDKI which is the more pathophysiological expected time frame for response given the rapid onset of action of LDKI. $[22,23]$

Additionally, the best dose of LDKI is yet to be defined. In our protocol we set a dose range of 1-10 $\mathrm{mcg} / \mathrm{kg} / \mathrm{min}(0.06-0.6 \mathrm{mg} / \mathrm{kg} / \mathrm{h})$ which is similar to the doses used in the majority of the other reported pediatric studies. Given we reviewed patients after protocol initiation, the majority of patients were started on the low end of the dose range given the median dose of LDKI was $0.06 \mathrm{mg} / \mathrm{kg} / \mathrm{h}(1 \mathrm{mcg} / \mathrm{kg} / \mathrm{min})$. Whether patients may have had a more meaningful response at higher doses is not clearly delineated by our or other studies. The single patient that required dose reduction in our retrospective analysis was on $2 \mathrm{mcg} / \mathrm{kg} / \mathrm{min}$ $(0.12 \mathrm{mg} / \mathrm{kg} / \mathrm{h})$ and reduced to $1 \mathrm{mcg} / \mathrm{kg} / \mathrm{min}(0.06 \mathrm{mg} / \mathrm{kg} / \mathrm{h})$. Coubarde et al. [9] similarly note that patients with side effects were all on lower doses $(<0.05 \mathrm{mg} / \mathrm{kg} / \mathrm{h})$. Our study has multiple limitations including: 1) being a retrospective analysis; 2) having a small, heterogenous cohort and 3) lacking an $a$ prioridefinition of best pain scores to compare and what entails a clinically meaningful result.

Since initiation of our LDKI protocol, empirically we have seen that certain patients with sickle cell disease and chronic pain perceive benefit with LDKI while others do not, not dissimilar to certain patients who prefer hydromorphone to morphine and vice versa. We have also empirically seen that many patients with chronic pain and at end of life are maintained on higher doses (i.e., $3-10 \mathrm{mcg} / \mathrm{kg} / \mathrm{min}, 0.18-0.6 \mathrm{mg} / \mathrm{kg} / \mathrm{h}$ ). Understandably, some patients may be benefiting due to a placebo effect especially with the use of a "new" 
intervention. Yet, overall, unlike adult patients who may not tolerate LDKI well leading to lack of consensus on benefit, the limited studies in pediatric patients do not show high rates of side effects leading to intolerability or discontinuation, parallel to what we show here. [29-31] Thus, similar to the conclusion of Bredlau et al. [31], we believe that LDKI is well tolerated and may be a viable option for refractory pediatric cancer- and chronic sickle cell-related pain and therefore should be offered routinely for these indications and assessed for benefit. Future study is required to further delineate appropriate dosing and the pediatric hematology/oncology patients most likely to benefit as well as to explore utilizing LDKI in the outpatient setting.

\section{CONFLICT OF INTEREST STATEMENT}

There are no relevant conflicts of interest for any author

\section{ACKNOWLEDGEMENTS}

Funding from the Northern Nevada Childhood Cancer Foundation for supportive care research

\section{REFERENCES}

1. Zempsky WT, Loiselle KA, McKay K, et al. Retrospective evaluation of pain assessment and treatment for acute vasoocclusive episodes in children with sickle cell disease. Pediatr Blood Cancer 2008;51:265268.

2. Collins JJ, Grier HE, Kinney HC, et al. Control of severe pain in children with terminal malignancy. J Pediatr 1995;126:653-657.

3. R3 Report: Pain assessment and management standards for hospitals. Issue 11, August 29, 2017. www.jointcommission.org

4. Finkel JC, Pestieau SR, Quezado ZM. Ketamine as an adjuvant for treatment of cancer pain in children and adolescents. J Pain 8:515-521.

5. Dowell D, Haegerich TM, Chou R. CDC guideline for prescribing opioids for chronic pain - United States, 2016. MMWR Recomm Rep. 2016;65:1-49.

6. Field JJ. Five lessons learned about long-term pain management in adults with sickle cell disease. Hematology Am Soc Hematol Educ Program 2017;406-411.

7. Zhu H, Brodsky M, Gorman AL, Inturrisi CE. Region-specific changes in NMDA receptor mRNA induced by chronic morphine treatment are prevented by the co-administration of the competitive NMDA receptor antagonist LY274614. Brain Res Mol Brain Res 2003;114:154-162.

8. Ketamine pharmacology: An update (pharmacodynamics and molecular aspects, recent findings). CNS Neurosci Ther 2013;19:370-380.

9. Courade M, Bertrand A, Guerrini-Rousseau L, et al. Low-dose ketamine adjuvant treatment for refractory pain in children, adolescents and young adults with cancer: A pilot study. BMJ Support Palliat Care 2019;1-8.

10. Kajiume T, Sera Y, Nakanuno R, et al. Continuous intravenous infusion of ketamine and lidocaine as adjuvant analgesics in a 5-year-old patient with neuropathic cancer pain. J Palliat Med 2012;15:719722 .

11. White MC, Hommers C, Parry S, Stoddart PA. Pain management in 100 episodes of severe mucositis in children. Paediatr Anaesth 2011;21:411-416.

12. James PJ, Howard RF, Williams DG. The addition of ketamine to a morphine nurse- or patientcontrolled analgesia infusion (PCANCA) increases analgesic efficacy in children with mucositis pain. Paediatr Anaesth 2010;20:805-811.

13. Conway M, White N, St. Jean C, Zempsky WT, Steven K. Use of continuous intravenous ketamine for end-stage cancer pain in children. J Pediatr Onc Nurs 2009;26:100-106.

14. Anghelescu DL, Oakes LL. Ketamine use for reduction of opioid tolerance in a 5-year-old girl with end-stage abdominal neuroblastoma. J Pain Symptom Manage 2005;30:P1-P3.

15. Tsui BC, Davies D, Desai S, Malherbe S. Intravenous ketamine infusion as an adjuvant to morphine in a 2-year-old with severe cancer pain from metastatic neuroblastoma. J Pediatr Hematol Oncol 
2004;26:678-680.

16. Klepstad P, Borchgrevink P, Hval B, Flaat S, Kaasa S. Long-term treatment with ketamine in a 12year-old girl with severe neuropathic pain caused by a cervical spinal tumor. J Pediatr Hematol Oncol 2001;23:616-619.

17. Fine PG. Low-dose ketamine in the management of opioid non-responsive terminal cancer pain. J Pain Symptom Manage 1999;17:296-300.

18. Nobrega R, Sheehy KA, Lippold C, Rice AL, Finkel JC, Quezado ZM. Patient characteristics affect the response to ketamine and opioids during the treatment of vaso-occlusive episode-related pain in sickle cell disease. Pediatr Res 2018;83:445-454.

19. Neri CM, Pestieau SR, Young H, Elmi A, Finkel JC, Darbari DS. Low-dose ketamine for children and adolescents with acute sickle cell disease related pain: a single center experience. J Anesth Clin Res 2014;5:394-398.

20. Tawfic AQ, Faris AS, Kausalya R. The role of a low-dose ketamine-midazolam regimen in the management of severe painful crisis in patients with sickle cell disease. J Pain Symptom Manage 2014;47:334340.

21. Zempsky W, Loiselle KA, Corsi JM, Hagstrom NJ. Use of low-dose ketamine infusion for pediatric patients with sickle cell disease-related pain: a case series. Clin J Pain 2010;26:163-167.

22. Masaracchia MM, Sites BD, Lee J, Thomas JJ, Fernandez PG. Subanesthetic ketamine infusions for the management of pediatric pain in non-critical care settings: An observational analysis. Acta Anaesthesiologica Scandinavica 2019;63:1225-1230.

23. Sheehy KA, Muller EA, Lippold C, Nouraie M, Finkel JC, Quezado ZM. Subanesthetic ketamine infusions for the treatment of children and adolescents with chronic pain: A longitudinal study. BMC Pediatr 2105;15:198.

24. Rowbotham MC. What is a "clinically meaningful" reduction in pain? Pain 2001;94:131-132.

25. Cepeda MS, Africano JM, Polo R, Alcala R, Carr DB. What decline in pain intensity is meaningful to patients with acute pain? Pain 2003;105:151-157.

26. Farrar JT, Young Jr. JP, LaMoreaux L, Werth JL, Poole RM. Clinical importance of changes in chronic pain intensity measured on an 11-point numerical pain rating scale. Pain 2001;94:149-158.

27. Myrvik MP, Brandow AM, Drendel AL, et al. Clinically meaningful measurement of pain in children with sickle cell disease. Pediatr Blood Cancer 2013;60:1689-1695.

28. Brandow AM, DeBaun MR. Key components of pain management for children and adults with sickle cell disease. Hematol Oncol Clin North Am 2018;32:535-550.

29. Hardy J, Quinn S, Fazekas B, et al. Randomized, double-blind, placebo-controlled study to assess the efficacy and toxicity of subcutaneous ketamine in the management of cancer pain. J Clin Oncol 2012;30:3611-3617.

30. Jackson K, Franco M, William L, et al. Ketamine and cancer pain: the reports of my death have been greatly exaggerated. J Clin Oncol 2013;31:1373-1374

31. Bredlau AL, Thakur R, Korones DN, Dworkin RH. Ketamine for pain in adults and children with cancer: A systematic review and synthesis of the literature. Pain Med 2013;14:1505-1517.

Supporting Material: Ketamine infusion management protocol

\section{Hosted file}

TABLE 1 LDKI manuscript.pdf available at https://authorea.com/users/373392/articles/491095low-dose-ketamine-infusion-for-pediatric-hematology-oncology-patients-case-series-andliterature-review

\section{Hosted file}

TABLE 2 LDKI manuscript.pdf available at https://authorea.com/users/373392/articles/491095low-dose-ketamine-infusion-for-pediatric-hematology-oncology-patients-case-series-andliterature-review 


\section{Hosted file}

TABLE 3 LDKI manuscript.pdf available at https://authorea.com/users/373392/articles/491095low-dose-ketamine-infusion-for-pediatric-hematology-oncology-patients-case-series-andliterature-review

\section{Hosted file}

TABLE 4 LDKI manuscript.pdf available at https://authorea.com/users/373392/articles/491095low-dose-ketamine-infusion-for-pediatric-hematology-oncology-patients-case-series-andliterature-review 